\title{
Effect of some therapeutics and immunostimulants on the course of Brucellosis in naturally infected sheep and goats
}

\author{
M. N. El-Sheery \\ Department of veterinary medicine, Faculty of Veterinary Medicine, Suez-Canal University
}

\begin{abstract}
In this study a total of 14 infected sheep and 6 lactating albino goats were used. These animals were proved to be brucellosis seropositive using TAT, MET, BAPAT, RBPT and rivanol test as well as bacteriologically positive by isolation of Brucella melitensis biovar 3 from their milk. These animals were subjected to trials of treatment using three different methods. Goats treated by antibiotics combined with BCG showed the highest recovery rate (on bacteriological basis), followed by animals treated with antibiotics only and finally animals treated with antibiotics combined ID. The recovered treated animals were placed under careful investigation for 2 years with no evidence of Brucella infection neither in them nor in their newborns.
\end{abstract}

Brucellosis is still one of the most important highly contagious diseases of animals and of great zoonotic importance in most countries of the world. The disease causes severe economic losses and its control constitutes incredible problem, as there is no ideal test or vaccine which can be used for its control, (Morgan, et al., 1969); Hunter and Allen, (1972) and Fensk, (1977), and presence of many carriers including domestic wild animals, Kataz, (1941) and stray dogs as well as rodents, (Salem et al., 1975).

Recently a great progress has been achieved in the filed of specific and non-specific immuneostimulants in the treatment of some infectious diseases.

The aim of present study was to investigate the effect of some immunostimulants combined with antibiotics on the treatment of sheep and goats naturally infected with Brucellosis under filed circumstances.

\section{Material and Methods}

Animals. A total of 14 Finland sheep and 6 Albino goats naturally infected with brucellosis (proved by bacteriological and serological studies) were classified into three groups. Group I contained 4 sheep and 2 goats while groups II and III, each contained 5 sheep and 2 goats.

Non-specific immunostimulants.

BCG vaccine. It was obtained from Vaccine and Sera Research Institute, Abbassia and was injectted as $0.1 \mathrm{ml} \mathrm{I} / \mathrm{D}$ in the first day of treatment.

Immunodynaminc (ID1). It is derived from components of the first bovine colostral milk and composed of specific antibody protein and nonspecific protein, which trigger the defense system in animals to control infectious agents. It was obtained from Immunodynamic, INC Perry, Owa 50220, USA. ID1 was used as $8 \mathrm{ml} /$ animal through $\mathrm{I} / \mathrm{M}$ injection for 3 successive days at the beginning of treatment.

Chemotherapeutic agents:

Tetracycline LA. It was obtained from Pfizer Company and injected at the rate of $20 \mathrm{mg} / \mathrm{kg}$ B.W. every 3 days for 6 weeks.

Streptomycin. It was obtained from Pfizer Company and was used in a dose rate of $20 \mathrm{mg} /$ $\mathrm{kg} \mathrm{B.W.} \mathrm{daily} \mathrm{for} 6$ weeks.

Protocol of treatment.

a) Animals of group I were treated by tetracycline LA every three day and streptomycin daily for 6 weeks.

b) Animals of group II were treated as in group I with addition of BCG vaccine injection in the first day.

c) Animals of group III were treated as in group I with addition of ID1, $8 \mathrm{ml} /$ animal for 3 successive days at the beginning of treatment.

Samples.

a) Serum samples were collected at the first day of treatment then every 15 days (4 times) and then every 3 months for serodiagnosis of brucellosis.

b) Colostrums, fetal membranes, fetal fluids and synovial fluid from capped knee were collected for isolation of Brucella organisms.

Serological tests (TAT, MET, BAPAT, RBPT and Rivanol test) and bacteriological examina-tion for isolation and typing of Brucella organi-sms were done according to Alton et al., (1988).

\section{Results and Discussion}


Table (1): Results of TAT.

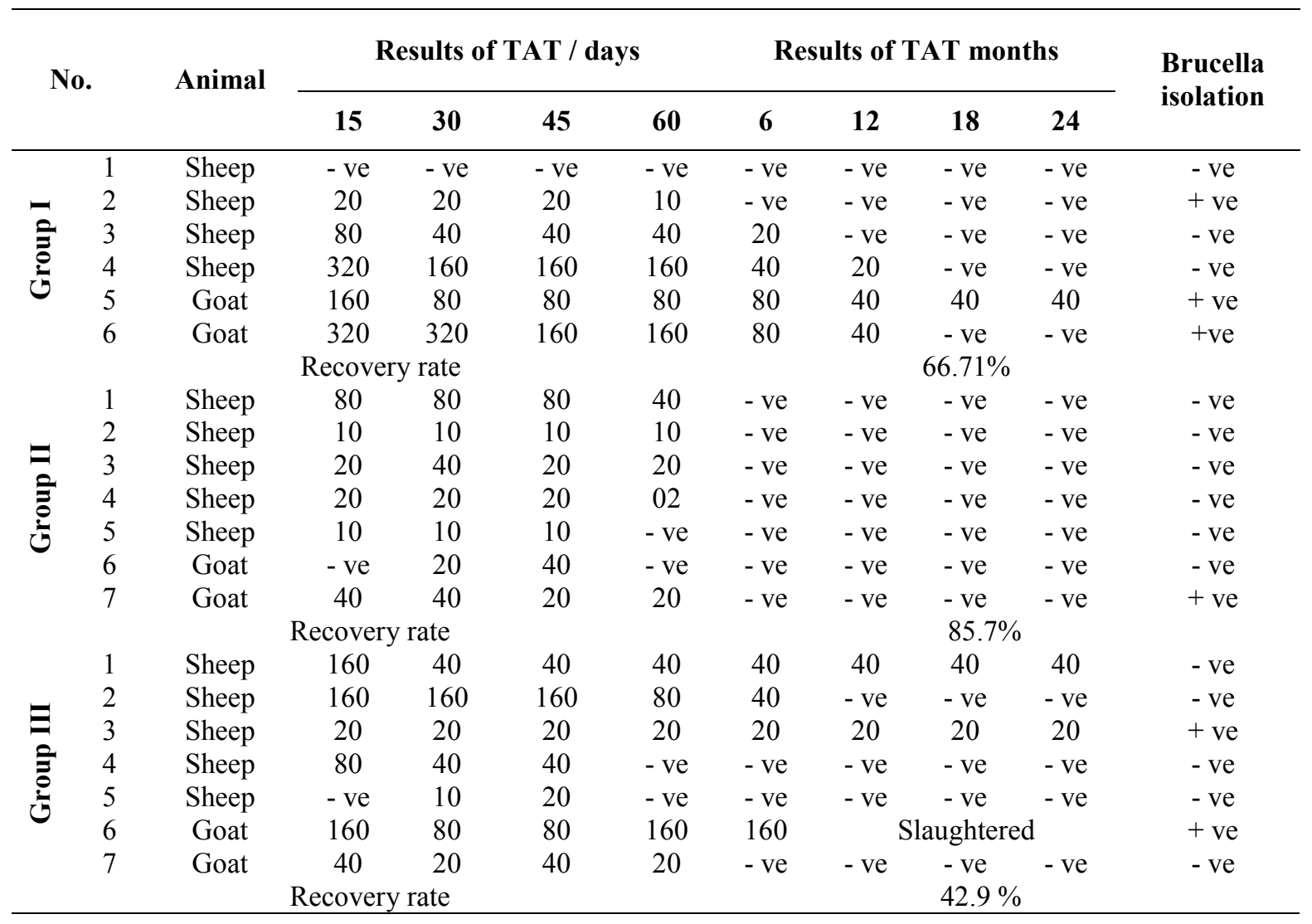

Table (2): Results of Rivanol test.

\begin{tabular}{|c|c|c|c|c|c|c|c|c|c|c|c|}
\hline \multirow{2}{*}{$\mathbf{N}$} & & \multirow{2}{*}{ Animal } & \multicolumn{4}{|c|}{ Results of TAT/ days } & \multicolumn{4}{|c|}{ Results of TAT months } & \multirow{2}{*}{$\begin{array}{l}\text { Brucella } \\
\text { isolation }\end{array}$} \\
\hline & & & 15 & 30 & 45 & 60 & 6 & 12 & 18 & 24 & \\
\hline \multirow{6}{*}{ } & 1 & Sheep & - ve & - ve & 50 & - ve & $-\mathrm{ve}$ & $-\mathrm{ve}$ & $-\mathrm{ve}$ & - ve & - ve \\
\hline & 2 & Sheep & 50 & 50 & 50 & - ve & - ve & - ve & - ve & - ve & Isolation +ve \\
\hline & 3 & Sheep & 100 & 50 & 25 & - ve & - ve & - ve & - ve & - ve & - ve \\
\hline & 4 & Sheep & 400 & 400 & 200 & 100 & 100 & 50 & - ve & - ve & - ve \\
\hline & 5 & Goat & 400 & 400 & 200 & 50 & 50 & 50 & 50 & 50 & $+\mathrm{ve}$ \\
\hline & 6 & Goat & 400 & 400 & 400 & 200 & - ve & - ve & - ve & - ve & - ve \\
\hline \multirow{7}{*}{ 园 } & 1 & Sheep & 200 & 200 & 200 & 100 & - ve & - ve & - ve & - ve & - ve \\
\hline & 2 & Sheep & $-\mathrm{ve}$ & - ve & - ve & - ve & - ve & $-\mathrm{ve}$ & $-\mathrm{ve}$ & - ve & - ve \\
\hline & 3 & Sheep & 25 & 100 & 50 & 25 & - ve & - ve & - ve & - ve & - ve \\
\hline & 4 & Sheep & - ve & - ve & 25 & - ve & - ve & - ve & - ve & - ve & - ve \\
\hline & 5 & Sheep & 25 & 50 & 25 & - ve & - ve & - ve & - ve & - ve & - ve \\
\hline & 6 & Goat & 50 & 100 & 25 & 25 & - ve & - ve & - ve & - ve & $+\mathrm{ve}$ \\
\hline & 7 & Goat & - ve & 25 & 50 & - ve & - ve & $-\mathrm{ve}$ & - ve & - ve & - ve \\
\hline \multirow{7}{*}{ 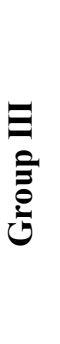 } & 1 & Sheep & 400 & 100 & 100 & 25 & 25 & 25 & 50 & 50 & + ve \\
\hline & 2 & Sheep & 200 & 200 & 100 & 50 & - ve & - ve & - ve & - ve & - ve \\
\hline & 3 & Sheep & 50 & 50 & 25 & - ve & - ve & - ve & - ve & - ve & + ve \\
\hline & 4 & Sheep & 100 & 100 & 50 & - ve & - ve & - ve & - ve & - ve & - ve \\
\hline & 5 & Sheep & - ve & - ve & 25 & - ve & - ve & - ve & - ve & - ve & - ve \\
\hline & 6 & Goat & 200 & 200 & 100 & 100 & 100 & \multicolumn{3}{|c|}{ Slaughtered } & $+\mathrm{ve}$ \\
\hline & 7 & Goat & 25 & 50 & 25 & - ve & - ve & - ve & - ve & - ve & - ve \\
\hline
\end{tabular}


Control of brucellosis in infected animals by slaughtering of infected cases constitutes major The present study involved a trial to investigate the efficiency of some chemotherapeutics economic loss especially in valuable sheep and goats either alone or in combination with non-specific immunostimulants on brucellosis in naturally infected valuable sheep and goats.

Streptomycin was the first aminoglycosides isolated in 1944 and still widely used in synergism with oxytetracyclin for treatment of brucellosis, (Madkour, 1989 and Richardson and Halt, 1962). These two antibiotics when combined with enhancement of cell mediated immunity by an immunopotentiating agent could be beneficial in control of brucellosis, Raptopoulou-Gigi, et al., (1980). The use of BCG vaccine in animals of group II as immunopotentiating agent showed a high rate of recovery (on bacteriological basis) 6 (85.7\%) while one goat $(14.3 \%)$ did not respond to treatment (Table 1,2). This high rate of recovery may be due to activation of macrophages by BCG, (Anderson and Reynolds, 1979).

In animals of group III in which ID1 as immunopotentiating agent combined with antibiotics, there was a lower recovery rate 4 $(57.1 \%)$ and $3(42.9 \%)$ did not respond to treatment. This can be explained on the basis of ID1 stimulates mainly the antibody production while Brucella organisms are intracellular microorganisms that are mainly affected by the cell mediated immunity, (Gruner, et al., 1985), but this differs from that reported by Shalaby, et al., (1994), who stated that ID1 could stimulate both cellular and humoral immunity.

In the first group in which animals were treated by tetracycline LA / streptomycin without immunostimulant, recovery rate was lower than that of BCG treated group but higher than of ID1 group, the rate of recovery was 4 $(66.7 \%)$ where as $2(33.3 \%)$ did not respond to treatment. These results differ from that reported by (Loward, et al., 1984) who recorded $71.4 \%$ recovery, and by (Radwan, et al., 1992) who recorded $93.7 \%$ recovery, when used tetracycline LA in a dose $20 \mathrm{mg} / \mathrm{kg}$ BW every 3 days for 3 weeks and $100 \%$ recovery when used tetracycline LA $25 \mathrm{mg} / \mathrm{kg}$ BW every 2 days for 4 weeks together with streptomycin $20 \mathrm{mg} / \mathrm{kg} \mathrm{BW}$ every 2 days for 2 weeks. In most cases, the antibody level decreased gradually with treatment which may be due to the immunosuppressive effect of oxytetracycline and or the inhibition of bacterial growth, (Tran, 1982).

The evaluation of the efficiency of treatment trials must based on serological and careful bacteriological investigation and/or PCR examination of the treated negative cases, as Brucella melitensis could be isolated from some serologically negative treated cases, (Nicoletti et al. 1985). Recovered treated animals and their newborns were bacteriologically and serologically investigated for 2 years and none of these animals and their newborns showed evidence of Brucella infection. This indicates high efficiency of such treatment especially in recently infected animals.

The present study suggests the importance of the use of antibiotics and immunostimulants during the outbreaks of brucellosis as an additional step to minimize the spread of the microorganism to susceptible animals.

\section{References}

Alton, G. G.; Jones, L. M.; Angus, R. D and Verger, J. M. (1988): Laboratory techniques in brucellosis INR publication, Paris, ISEN, France.

Anderson, A. O. and Reynolds, J. A. (1979): Adjuvant effect of lipid amine, C. P. 2096, J. Reticulend. Soc. 26: 667-669.

Fenske, G. (1977): Sensitivity and specificity of serological tests for bovine brucellosis. Manatshefte Fur Veterinar Medizin, L 32: 18-24.

Gruner, S. M.; Lenk, R. P. and Janoff, A. S. (1985): Novel multilayer lipid vesicles, comparison of physical characteristics of multilamellar lipid and stable plurilamellar vesicles. Biochem. 24: 2833-2842.

Hunter, D. and Allen, J. (1972): An evaluation of milk and blood tests used to diagnose brucellosis. Vet. Rec., 91: 310-312.

Kataz, J. C., (1941): Brucellosis in wild life. J. Am. Vet. Med. Assoc., 99: 24.

Loward, F. W.; Nicoletti, P. and Hoiffman, E., (1984): Effectiveness of various therapeutics regimes for bovine brucellosis. Am. J. Vet. Res., 45 (9): 1825-1828.

Madkour, M. M., (1989): Brucellosis, $1^{\text {st }}$ ed. 219. Printed in UK, Univ. Press, Cambridge.

Morgan, W. J. B.; Mockinon, D. J. and Cullen, G. A. (1969): The Rose Bengal plate agglutination in the diagnosis of brucellosis. Vet. Rec., 85: 636-641.

Nicoletti, P.; Lward, F. W.; Hoffman, E. and Altvater, L., (1985): Efficiency of long acting oxytetracycline alone or combined with streptomycin in the treatment of bovine brucellosis. J. Am. Vet. Med. Assoc., 187 (5): 493-495.

Radwan, A. I.; Bekairi, S. I. and Mukayel, A. A., (1992): Rev. Sci-Tech., 11 (3): 845-857.

Raptopoulou-Gigi, M.; Kountouras, J. and Goulis, G., (1980): Levamisol in treatment of chronic brucellosis. J. Immunopharm. 2: 85-97.

Richardson, M. and Halt, J. N., (1962): Synergistic action of streptomycin with other antibiotics on intracellular Brucella abortus in vitro. J. Bact., 84: 638-646. 
Salem, A. A.; Hamed, O. M. and Abdel-Karim, A. H., (1975): Studies on some Brucella carriers in Egypt. Assuit Vet. Med. J., 1: 181-187.

Shalaby, M. A.; Khafagy, A. A.; Wayer, M. A. and
Darwish, K. (1994): Second Conference of the Egyptian Association of Immunogenesis.

Tran, Din, H. T., (1982): Effect of antibiotic on the development of immune response in the organisms of animals. Scientarum Hungaricae, 29 (2): 127-141. 